\title{
LA SEMIOSIS: CASCADA DE SIGNIFICACIÓN
}

\author{
Floyd Merrell
}

\author{
(Purdue University)
}

\begin{abstract}
Me centraré en la transformación de los signos en signos: el proceso semiósico según el cual la producción de significación es continua, sin comienzo, fin, ni centro alcanzable para el agente semiótico finito y falible. Somos, a fin de cuentas, signos, nosotros mismos, suspendidos dentro de la compleja red de significación.
\end{abstract}

\section{EL SIGNO TRIÁDICO}

La entidad semiótica fundamental del signo peirceano consiste en un representamen (signo), un objeto (no «real» sino de lo «real semiótico»), y un interpretante (comparable, más o menos, con el significado saussureano). En concierto con estas entidades, hay un conjunto elaborado de tríadas, que incluye, entre otras, cualisignos, sinsignos y legisignos, iconos, índices y símbolos, y términos, proposiciones y argumentos. Todas estas categorías corresponden a las de primeridad («Firstness»), segundidad («Secondness») y terceridad («Thirdness») respectivamente (véase las tres tríadas en la tabla 1 ). 


\section{Tabla I}

\begin{tabular}{|c|c|c|c|}
\hline & $\begin{array}{c}\text { «epresentamen (R) } \\
\text { Primera }\end{array}$ & $\begin{array}{c}\text { Objeto (O) } \\
\text { Segunda }\end{array}$ & $\begin{array}{c}\text { Interpretante (I) } \\
\text { Tercera }\end{array}$ \\
\hline $\begin{array}{c}\text { Cualidad } \\
\text { («Firstness») }\end{array}$ & Cualisigno & Icono & Rema (término) \\
\hline $\begin{array}{c}\text { Actualidad } \\
(\ll \text { Secondness })\end{array}$ & Sinsigno & Índice & $\begin{array}{c}\text { Dicente } \\
\text { (proposición) }\end{array}$ \\
\hline $\begin{array}{c}\text { Generalidad, } \\
\text { ley, hábito } \\
(\ll \text { Thirdness») }\end{array}$ & Legisigno & Símbolo & Argumento \\
\hline
\end{tabular}

El prefijo cuale es tono, sentimiento, vaguedad, lo que aún no goza de especificación. Sin se deriva de alguna singularidad, unicidad; es un rasgo nominal («token») que ocurre una vez y sólo una vez. Legi, en contraste, implica repetición, uso, replicación, lo que llega a ser, por el hábito, un tipo («type») general. Un icono es cualquier signo que significa algo por una asociación de similitud $(C P: 3.362)$. Es un signo «que se refiere al objeto que denota solamente por la virtud de sus propias características, las que poseería también este signo, exista o no el objeto... Cualquier cosa, sea cualidad [primeridad], individuo existente [segundidad], o ley [terceridad], es un icono de cualquier cosa en tanto que se parezcan y es usado como un signo del objeto» ( $C P: 2.247)$. Ejemplos típicos de iconos son imágenes, cuadros de pintura, metáforas, diagramas, caricaturas, en fin todos los signos que tienen algo parecido a algo más $(C P: 2.92,4.418)$.

Un índice «es un representamen que cumple la función de un representamen por virtud de la característica que no tendría si su respectivo objeto no existiera, pero que continuaría teniendo, sea o no sea interpretado como un representamen» (CP:5.37). El índice dirige la atención de su intérprete al objeto por causa de alguna conexión (sea de lo «real semiótico» o no) con su «objeto semiótico». Por ejemplo, una veleta es un índice de la dirección del aire de la misma manera en que un barómetro 
es un índice de la lluvia. Ya que hay una relación entre el índice y su objeto (de lo «real semiótico», no lo «real» verídico), lo que no tiene un icono, el índice debe transmitir información respecto a su objeto, aunque no sea necesario que lo describa.

El símbolo «es el nombre general de una descripción que significa su objeto por medio de una asociación de ideas o una conexión habitual entre el nombre y el elemento significado» $(C P: 1.369)$. Una distinción entre un símbolo, de un lado, y un icono o índice, del otro, es que para aquél no es necesaria una conexión natural con su cualidad material para funcionar como signo significando el objeto que representa. La conexión puede ser puramente mental, y en el comienzo puede ser en parte arbitraria, aunque luego se vuelva necesaria por medio de convenciones sociales. El lenguaje natural, como es obvio, es el ejemplo por excelencia de los símbolos. Por ejemplo, la enunciación, «El universo está formado por átomos», es, como entidad propia, un símbolo compuesto de símbolos más sencillos de varios tipos representando su objeto. El significado de esta composición de símbolos estriba en la propensión de la mente a asociar «universo» y «átomos» con lo que construye como el objeto -un objeto imaginado o «semióticamente real»- en vez de «real» de la enunciación. Asî que la función de cada símbolo es la de representar su objeto como resultado de alguna asociación convencional.

De los signos icono-índice-símbolo, ligados con cualisigno-sinsignolegisigno y rema (término)-dicisigno (proposición)-argumento, según está ilustrado en la tabla I, Peirce desarrolló su decálogo fundamental de signos (véase las tablas II y III). Nótese que la tabla II demuestra, por las líneas de eslabón, cómo las nueve categorías de la tabla I combinan para generar las diez clases básicas de signos de la tabla III. La columna central de esta tabla provee la nomenclatura para los diez signos, la columna a la derecha da un ejemplo de cada uno, y la columna a la izquierda demuestra la composición de los signos, desde las tres categorías de Primera a las de Tercera.

Se puede ilustrar los diez signos básicos de Peirce de manera más abstracta, según la figura 1 , representada en forma más geométrica - siguiendo el ejemplo de Robert Marty (1982) - en la figura 2. Las notaciones, $R, O$ e $I$, y sus subscritos - que coinciden con la columna a la izquierda de la tabla III- corresponden a los representámenes (signos), objetos (referentes) e interpretantes (significados), y a las categorías de primeridad, segundidad y terceridad, respectivamentel. Estos tres componentes de los signos, designados por los subscritos, se generan, al progresar desde la parte «inferior» del esquema de la figura 1 hacia la parte

1 En realidad, no fue la intención de Peirce el que el signo fuera considerado sinónimo del representamen (véase Savan 1987-88:15). Un "objeto semiótico" puede ser el signo de otro "objeto semiótico", y éste aún de otro, y así sucesivamente; y un interpretante es el signo de su precursor, que a su vez se convierte en otro signo, ad infinitum. 
Tabla II

\begin{tabular}{|l|l|l|}
\hline $1-1-1$ & (1) Cualisigno & Una sensación de «azul» \\
\hline $2-1-1$ & (2) Sinsigno Icónico & Un diagrama autosuficiente \\
\hline $2-2-1$ & (3) Sinsigno Remático Indicial & Un grito espontáneo \\
\hline $2-2-2$ & (4) Sinsigno dicente & Una veleta \\
\hline $3-1-1$ & (5) Legisigno Icónico & $\begin{array}{c}\text { Un diagrama, aparte de su } \\
\text { autosuficiencia }\end{array}$ \\
\hline $3-2-1$ & (6) Legisigno Remático Indicial & Un pronombre demostrativo \\
\hline $3-2-2$ & (7) Legisigno Dicente Indicial & Una expresión común \\
\hline $3-3-1$ & (8) Símbolo remático & Un término \\
\hline $3-3-2$ & (9) Símbolo Dicente & Una proposición \\
\hline $3-3-3$ & (10) Argumento & Un silogismo \\
\hline
\end{tabular}

Tabla III

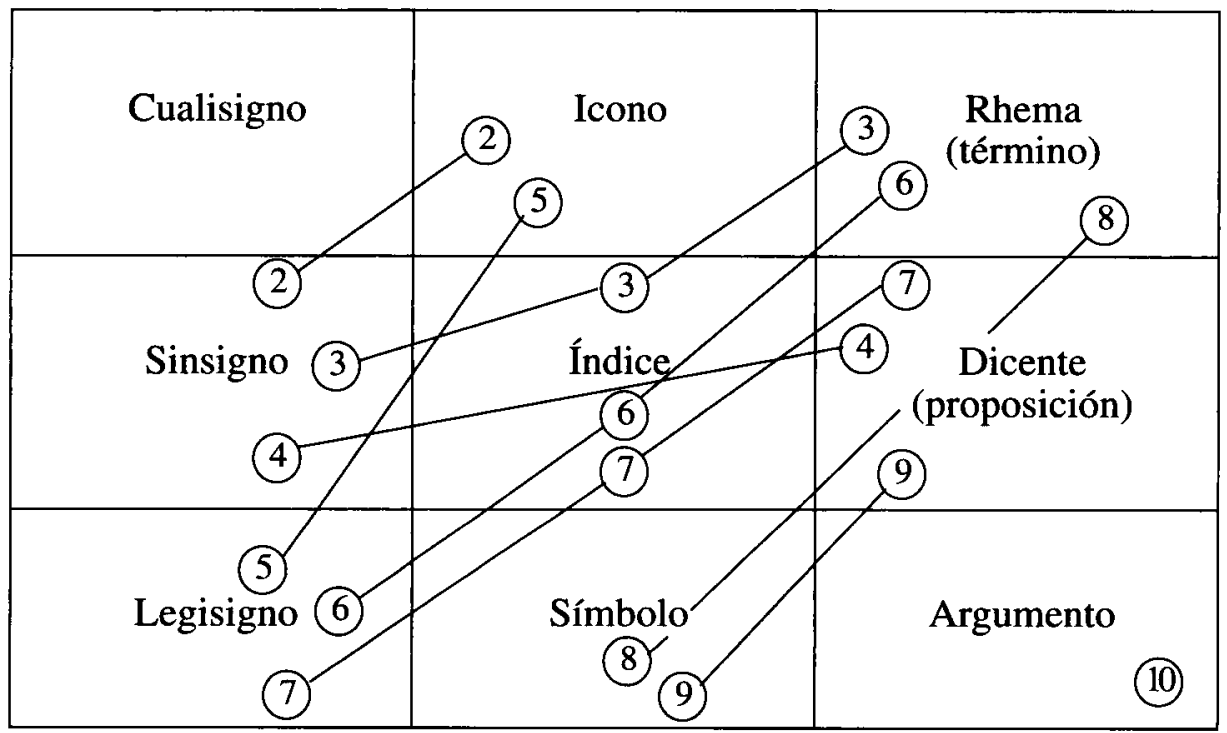




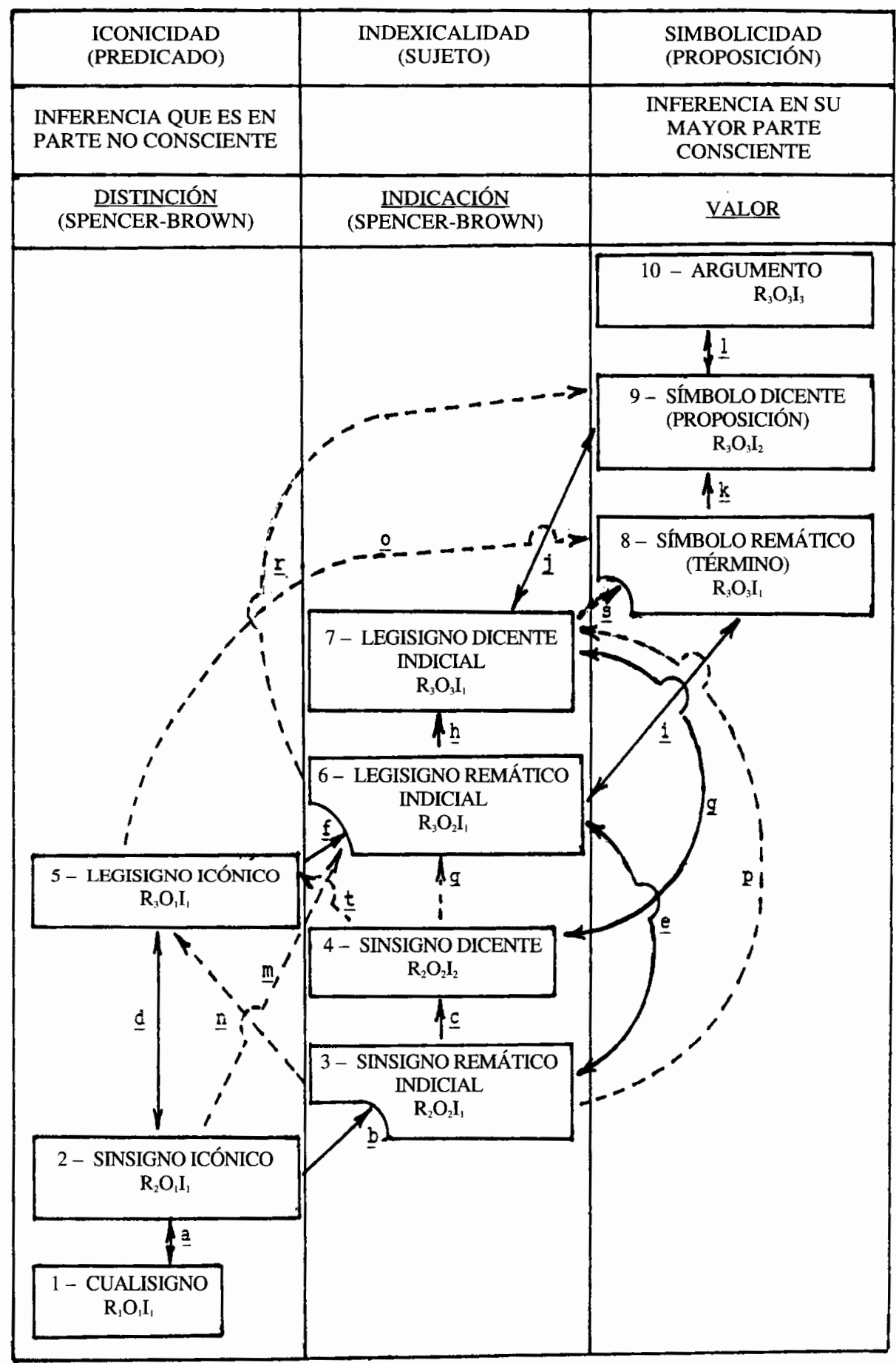

Figura 1 


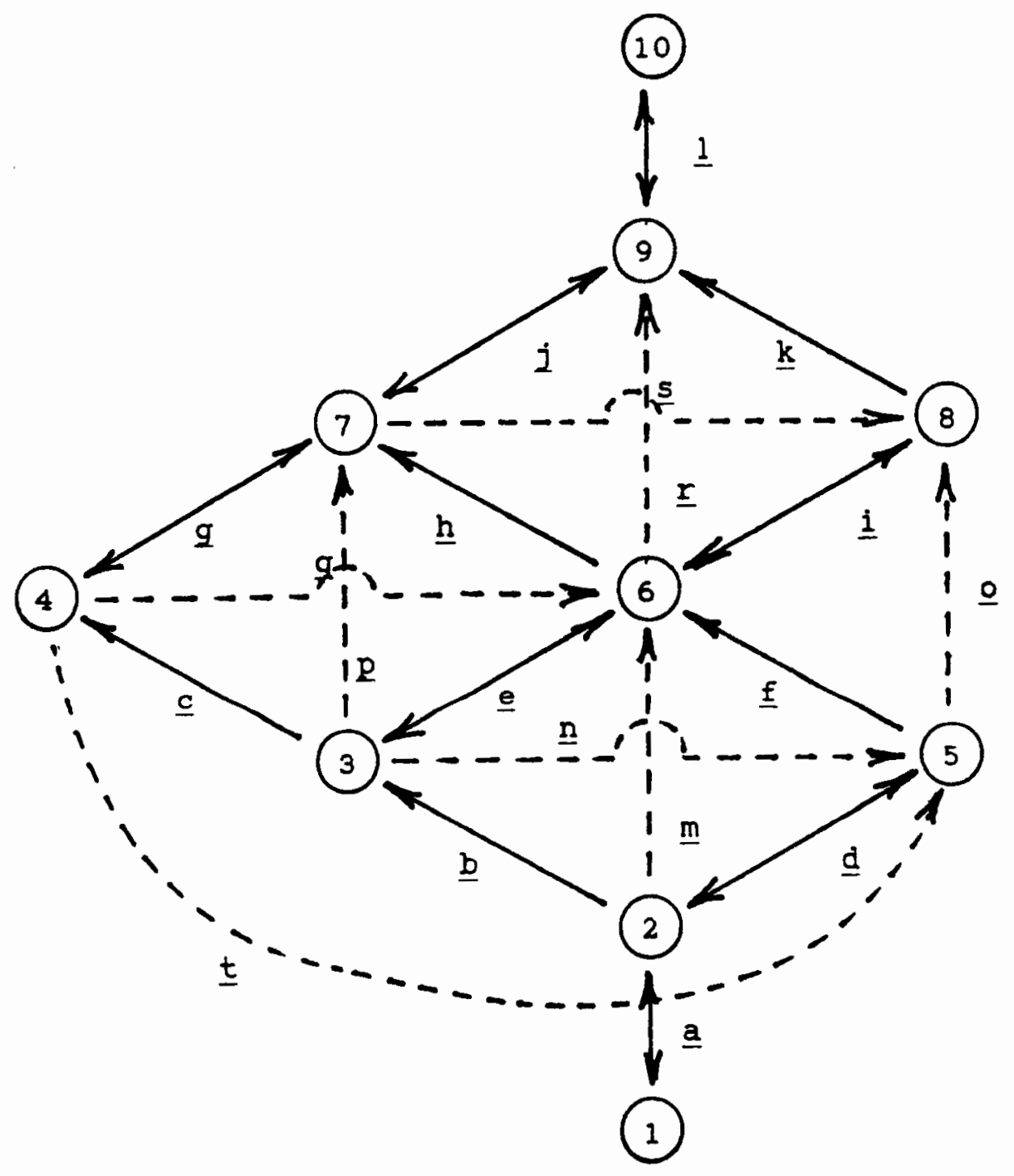

Figura 2 
«superior», o pueden de-generarse, de «arriba» hacia «abajo» 2 . Los subscritos indican los respectivos «modos de significación» de los signos, de primeridad (la posibilidad, un puede ser), a segundidad (la actualidad, lo que es), y a terceridad (la necesidad, lo que sería, de acuerdo con condiciones especificadas, por regla general, según los hábitos o costumbres idiosincráticos y las convenciones sociales) ${ }^{3}$. La primeridad es el modo de significación «de lo que es tal como es, positivamente y sin referencia a otra cosa» - un signo de sí mismo- La segundidad es «lo que es tal como es, con respecto a alguna otredad y sin terceridad». Y la terceridad es «lo que es tal como es, en el acto de mediar entre la segundidad y la primeridad» $(C P: 8.328)$.

Los tres modos de significación, $R, O$ e $I$ (representamen, objeto e interpretante) son las ejemplificaciones significantes fundamentales. Respecto a la figura 1, la función mediaria del $I$ se lleva a cabo a través de alguna similitud (subscrito 1, primeridad), una conexión semiótica (subscrito 2, segundidad), y/o un eslabón habitual, convencional o esencial (subscrito 3, terceridad). La conciencia de esta mediación depende de la esfera de lo «real semiótico», que a la vez depende de las convenciones de una comunidad humana particular. Lo «real semiótico», aunque nunca absolutamente coextenso con lo «real verídico» según Peirce -por la finitud y fiabilidad del agente semiótico- de todos modos puede aproximarlo de manera asintótica, si es que el agente semiótico goza de tal suerte.

Las letras en minúscula conectando los diversos signos en la figura 1 son operadores que transforman los signos de un tipo a otro 4 . Las flechas sólidas o continuas representan las rutas «normales» de la transmutación de los signos dentro de la matriz semiótica; las flechas discontinuas representan rutas «anormales». Una transmutación «anormal» abarca, o un

2 Para evitar confusión acerca de los llamados signos "degenerados", debo mencionar que de ninguna manera quiso Peirce denigrar a los iconos e índices y privilegiar los símbolos. Su uso del término "de-generado" es el de la matemática, distinto de su uso peyorativo en el habla popular. En realidad, los signos "de-generados" son más fundamentales, más esenciales para la comunicación, que los signos más "desarrollados", y sirven para modos de comunicación, sobre todo no-verbal, que quedan fuera del alcance de la semiosis propiamente simbólica.

En breves palabras los signos "de-generados" son inauténticos. Los símbolos completamente consumados -un sueño ideal, ya que tal perfección no existe en el reino de este mundo- son los únicos signos auténticos. Sin embargo, los iconos e índices no son sencillamente una dilución de símbolos; contienen la potencialidad para llegar a ser signos empapados de significación y capaces de poner a sus intérpretes en el camino hacia la plenitud semiótica (para estudios más detenidos sobre los signos "de-generados", véase Buczunska-Garewicz [1979a, 1979b]; Gorlée [1990]; Tursman [1987].

3 Limitaciones de tiempo y espacio no permiten una exposición detallada de las clases de signos de Peirce, aunque brevemente los elaboraré en las secciones que siguen. Véase David Savan (1987-88) para una de las mejores introducciones al sistema de signos del semiótico norteamericano. mal.

4 Marty (1982) usa el término functor en su exposición matemática más rigurosamente for- 
«brinco» por dos pasos en la evolución del $R, O$ o $I$, o un solo paso tomado por dos de los tres elementos del signo (denotados por los subscritos). En estos casos — para los cuales daré ejemplos abajo- una parte de la evolución general de los signos queda implícita. Es decir, la inferencia, que es un sine qua non para toda transformación semiótica según Peirce, está destinada a quedar cuando menos en parte fuera de la conciencia activa.

Las flechas hacia arriba, sean continuas o discontinuas, significan la generación, o evolución (semiosis), de signos relativamente «subdesarrollados» a los «desarrollados», y de signos relativamente simples a complejos. Además de la evolución hacia «arriba», incluyen la de-generación hacia «abajo»; es decir, lo que cualificaré como la automatización o arraigo (el carácter profundamente habitualizado) del uso de los signos. El arraigo de un signo significa su sumersión en la conciencia del agente semiótico de modo que su interpretación llega a ser tácita, implícita, y por lo tanto influye su acción respecto al signo como resultado de la naturaleza del interpretante. Como consecuencia, los signos relativamente complejos y «desarrollados» tienden a ser percibidos y concebidos como $s i$ fueran de un tipo más sencillo y menos «desarrollado», como, por ejemplo, el término «universo» concebido como si no fuera más que una «máquina» o el «cerebro» como si fuera una «computadora» (en los dos casos algo sumamente complejo es reducido a algo relativamente simple y comprehensible). Y por fin, las flechas que giran alrededor de cada uno de los diez signos indican instancias reiterativas del mismo signo, cada recursión de lo cual sirve como una alteración ( $\rightarrow$ diferenciación), por insignificante que sea, del signo (y por lo tanto la naturaleza del signo de la categoría segunda como una haecceidad, una singularidad, se destaca).

\section{EN BUSCA DE LA CORRIENTE PRINCIPAL DE SIGNIFICACIÓN}

Ahora fijémonos detenidamente en los diversos tipos de signos en las figuras 1 y 2 . En el nivel básico, el signo 1 es el cualisigno, una mera posibilidad o sensación, como, por ejemplo, la percepción inicial de «azul», sin que haya (todavía) alguna forma de conciencia de esta sensación de «azul» como tal. Este icono, por la operación $a$-la inclusión de la categoría segunda al representamen - se convierte en un sinsigno icónico, el signo 2, que consiste en un objeto de la experiencia cuya cualidad es determinada por la idea que motiva. Éste es un «signo de esencia», un icono también, sin conexión alguna con el objeto al cual puede en un momento en el futuro referir. 
En este nivel básico, no hay (todavía) nada como un «objeto semiótico», ni hay ningún interpretante especificando el lugar del «objeto semiótico» en el mundo de lo «real semiótico» (según el esquema conceptual de una comunidad dada), ni hay la sensación de algo (el signo 2) incorporando la mera posibilidad de esta sensación (el signo 1). Hay solamente el equivalente semiótico de una marca de distinción, siguiendo el cálculo sumamente elegante de G. Spencer-Brown (1979) que revela la división primordial del universo en dos entidades, algo que «ve» y algo que «es visto» - una separación de esto de aquello, «yo» del mundo-. Esta marca es semejante a lo que Peirce (CP:6.189-204) llama un corte («cut») en la «nada» de la posibilidad pura, el espacio puro, que es, por decirlo así, una categoría pre-primera (Baer 1988). El espacio, en el sentido ideal de Peirce, es continuo. La base del primer signo individual, comparable a la marca de distinción, se separa de esta «nada» como un fragmento aislado, sin sentido. Entonces, a medida que se hace signo y se transforma en signos cada vez más complejos, el conjunto de todos los signos comienza a converger y fusionarse, tomando poco a poco una semblanza continua y así tornándose una vez más como el espacio. A fin de cuentas, entonces, el universo de signos y el espacio se unen; los signos se crean y procrean, y a la vez crean el tiempo, en su vaivén por todos los rincones del espacio.

Sin embargo, hay una diferencia notable entre la marca de distinción de Spencer-Brown y el signo más básico de Peirce. Como operador del tipo más primitivo, la marca trae una potencia para indicar (como índice), en el espacio, el cruce de un límite en parte o en su totalidad arbitrario, para apartar lo que se puede denominar este, de su otro. Las letras en minúscula de la figura 1, en contraste, son una forma semiótica más avanzada que la marca en términos de su papel como operadores en transportar los signos de una categoría a otra en el proceso de que éstos llegan a ser algo más que, o menos que, pero siempre distinto de, lo que eran - lo que los coloca en un espacio significante nuevo-. Por ende la diferencia principal entre el operador primitivo de Spencer-Brown y los de la figura 1 descansa en la potencialidad de éstos como motivadores de significación, mientras que aquél es solamente un mecanismo de distinción, o cuando más de indicación, en el nivel más rudimentario, sin función sustancial o significadora alguna ${ }^{5}$. La marca, no obstante, posee, al establecer una distinción y una indicación, el papel esencial de

5 No puedo hacer demasiado hincapié en la importancia del concepto de Spencer-Brown de que en el nivel más profundo, los actos de distinción, indicación y nominación, exigen que un límite o margen deba ser "cruzado" para que haya la ejemplificación de un signo, y si se "cruza" de nuevo, queda la "nada". En contraste, en la esfera de lo "real semiótico", un nuevo "cruce" no deja al signo en su estado anterior. Siempre e invariablemente hay una diferencia, el reconocimiento de la cual, en el sentido más primitivo, quizás dé origen a lo que concebimos como la memoria (Spencer-Brown 1979: 62-68). 
los iconos y los índices ya que es lo que su otredad-que virtualmente indica- no es.

El operador $b$ presenta el objeto de la experiencia del signo en su forma más básica, como la evocación «iMira!», un rayo del cielo, o un estallido repentino, que llaman la atención a su causa. Este sinsigno remático indicial incorpora un sinsigno icónico de una índole particular para atraer la atención del destinatario del signo sin que exista (todavía) algo que pueda significar algo para él. Así es que el producto de $b$, que genera el primer rema, o sema, es la contraparte de la indicación de SpencerBrown (el «índice» que sigue la marca originaria). En este nivel el signo todavía no es más que una cualidad posible con la virtualidad de que puede ser incorporado en un objeto futuro. El rema también se aproxima a lo que Bertrand Russell denomina como una función proposicional (véase Savan 1987-88:41). Por ejemplo, la proposición incompleta «__ es azul», deja en blanco al sujeto, quedando tal blanco como una posibilidad vaguísima que puede llenarse en el futuro con un número indefinido de signos-objetos. Esta proposición, aunque esquelética, sin embargo ofrece una vista anticipatoria del signo 9, una proposición en su sentido cabal, el símbolo dicente.

La forma más básica de una proposición, según Peirce, consiste en un índice (sujeto) y un icono (predicado) $(C P: 2.438)$. En el caso de " es azul», el predicado se especifica, aunque queda indefinidamente vago, mientras el sujeto no es más que un conjunto vacío («empty set»), y por lo tanto un signo general en el sentido más amplio. Como ejemplo de la categoría primera pura, el signo, "____, es en cierto sentido completo, ya que indica la posibilidad de todos los signos que pueden llenar el vacío. Pero como signo auténtico queda indefinidamente incompleto, porque aún no especifica nada. Es una indicación sumamente simple, sin su vestidura de significación. O sea, los iconos y los índices de por sí no son capaces de afirmar nada en la forma de una proposición, porque una proposición exige una combinación de los dos componentes sígnicos $(C P: 2.291)$.

Tal como la distinción spencer-browniana queda incompleta sin su indicación correspondiente, así el operador $c$, que rinde la categoría tercera al representamen para llenar el «vacío» que dejó el operador $b$, genera el signo 4, el sinsigno dicente. Un ejemplo de este signo es una veleta que señala la dirección del viento al destinatario. Éste es el signo inicial que abre la puerta a la experiencia directa respecto al «objeto semiótico». El representamen es ahora virtualmente un signo cabal. Aquí encontramos igualmente el primer paso auténtico de la dualidad semiótica: la veleta es un signo del viento y a la vez un signo señalando la dirección del viento; significa el objeto y el efecto de una de sus propiedades. De esta manera incorpora los elementos primitivos de una enunciación: un sujeto (índice) y un predicado (icono). En un sentido diádico y comparable, una 
pintura (icono) con la firma del artista (índice), informa al destinatario respecto del sujeto tanto como del autor (Savan 1987-88:52). Por lo tanto contiene también los rudimentos de una proposición, como todos los signos $4(C P: 2.320)$.

La operación $d$ engendra el signo 5, un legisigno icónico (es decir, un sinsigno icónico aparte de su individualidad particular como rasgo singular [«token»], que es el primer signo de la naturaleza de una generalidad, o tipo («type»). Cada ejemplificación de este signo envuelve una cualidad específica, o icónica, que sirve para evocar en la mente una idea general - aunque a este nivel quede algo vago- del «objeto semiótico». Es de todos modos un icono, pero de una clase especial. Su modus operandi es el de gobernar una serie de ejemplificaciones singulares del «objeto», cada una de las cuales es un sinsigno icónico, en el camino hacia algún concepto general.

Esta operación es pertinente a las operaciones de re-iteración y condensación de Spencer-Brown formuladas en su axioma $1(71=7)$, que, en términos de la semiótica peirceana, dentro del contexto presente, sería: «Una distinción (icono-signo) repetida es igual que la primera distinción y el valor (símbolo-interpretante) indicado (como índice) dos veces es igual como si hubiera sido indicado sólo una vez» (Spencer-Brown 1979:1). Es decir, un signo, como una réplica o rasgo nominal («token») que se diferencia de cada una de las otras ejemplificaciones de este signo, se encamina hacia su culminación como tipo («type») en el sentido cabal. Para bien o para mal, así se forman las generalidades, como si la mera acumulación de instancias particulares pudiera terminar en una representación de naturaleza eterna, como si por la aceleración del stacatto se pudiera generar el legato. En este acto las diferencias se ignoran mientras las semejanzas a la fuerza se hacen identidades: a la larga un sueño platónico, utópico.

Sin embargo, nunca hay identidad absoluta después de cada re-iteración en el mundo de lo «real semiótico» (véase también Merrell 1985, 1991). Por ejemplo, Brian Rotman (1987) demuestra cómo la re-iteración de una marca genera la enumeración, I, II, III ... $n$, igual que palitos usados para la enumeración en las culturas «pre-matemáticas». Mientras en la esfera de la matemática esta regla general tiene vigor, con respecto al uso relativamente flojo de los signos en la vida cotidiana, el signo reiterativo y reflexivo termina inexorablemente en una recursión manchada de diferencias, por mínimas que sean: la re-ejemplificación del signo nunca es en cada uno de sus detalles lo que era; siempre es otro, algo diferenciado. No quiero decir que el cálculo de Spencer-Brown de distinciones e indicaciones primitivas no tenga que ver con el proceso semiósico, sino que se basa en un acto más básico de distinguir, indicar, y atribuir un valor («value», nombre) a lo que fue distinguido. En este nivel spencer-browniano más primordial, todos los actos de distinción e indi- 
cación de hecho son idénticos: consisten sencillamente en la creación de límites separando esto de aquello. Entonces todas las distinciones e indicaciones tienen la misma validez, al contrario de las sucesivas diferenciaciones respecto a las re-iteraciones semiósicas peirceanas.

Ahora bien, para que una distinción e indicación se destaquen como tal, se les debe atribuir un nombre, y subsecuentemente un valor particular. De hecho, una distinción no puede existir como tal sin su valor concomitante. Si a una distinción se le atribuye con el nombre, $X$, y si $X$ adquiere algún sentido para alguien, «Yo», entonces este «Yo» se ha apartado de $X(\ll$ Yo» $X)$ para que $X$ pueda ser un signo representando algo para alguien («Yo») en algún respecto u otro $-\mathrm{y}$ he aquí, la definición peirceana del signo en su forma más básica-. Así, $X$ contiene dentro de sí la potencialidad para llegar a ser un signo triádico auténtico como todos los signos 6 .

El equivalente del valor semiótico con respecto a la generación de los signos entra con los operadores $e$ y $f$, que unen los signos 3 y 5 en 6 . El signo 6, un legisigno remático indicial, «es cualquier tipo o ley general ... que requiere que cada una de sus ejemplificaciones estén afectadas por su objeto de manera que dirija la atención a ese objeto» (CP:-2.259). Cada réplica de este signo es a la vez un sinsigno remático indicial (sirviendo sólo para llamar la atención), un sinsigno dicente (ofreciendo el objeto de la experiencia directa del destinatario), y un legisigno icónico (contribuyendo al elemento de generalidad). Un pronombre relativo o demostrativo es el ejemplo prototípico de un sinsigno remático indicial. Pero queda radicalmente incompleto, ya que sufre una pérdida, por la operación $q$ de 4 a 6 , del estado segundo del interpretante - caso que discutiré más adelante.

La generación del signo 6 por el operador $e$ adjunta la categoría tercera al representamen; mientras la indicación de esto en oposición a aquello no es todavía el objeto definitivo de una especificación explícita. En contraste, $f$ transforma a 5 -que requiere la colaboración de un rema y un legisigno ( $C P: 2.258)$ - en 6 por la integración de la categoría segunda al objeto (por ejemplo, una veleta), para especificar lo que esto, ya que fue distinguido, es. El signo 6, distintivo tanto como indicacional, y ya cargado con los rudimentos de un valor, contrasta algo de algo más - la prioridad de esto en vez de aquello - un acto que envuelve la expresión primitiva de una relación binaria en el nivel segundo del «objeto semiótico». Además, el signo 6 forma lo que llama Peirce una cuasi-proposición. Es decir, otro paso en el desarrollo de la indexicalidad del sig-

6 Hay que tener en cuenta que Spencer-Brown habla del acto de nombrar, y no de la función de los nombres o los nombres de por sí. El mero acto de nombrar, por decirlo así, es en cierta manera una pre-sintaxis, y no tiene nada que ver con la posición del nombre dentro de la estructura de una secuencia de signos en una enunciación. 
no lo lleva cada vez más cerca de su papel como sujeto auténtico en una proposición, lo que, se supone, es la meta última del desarrollo del signo. Como resultado, 6 incorpora su información en la forma de una afirmación sobre algo existente. Este algo, como un objeto que ya tiene cierto valor - aunque todavía vago- va encaminándose hacia un sujeto (índice) cabal que, combinado con un predicado (icono), formará una proposición que compone parte de un argumento - la culminación del decálogo peirceano de los signos.

Los operadores $n, q$ y $s$ marcan una reducción o cancelación: (1) o del «objeto semiótico» $(0$ por la operación $n)$, (2) o del interpretante ( $I$ por las operaciones $q$ y $s$ ). Esta reducción es aproximadamente la contraparte peirceana del axioma 2 de Spencer-Brown, la «ley de los límites» $(\Pi=\mathbb{Z})$, que, en términos semióticos, sería: «Si el margen que separa lo que el signo es de lo que no es se establece, y luego se vuelve a establecer, el valor indicado por los dos actos es igual que si no hubiera habido ningún acto» (Spencer-Brown 1979:2). Ha habido una cancelación — absoluta en el sentido spencer-browniano, y parcial en el sentido semiótico- o del «objeto semiótico», o del interpretante, dejando otra vez la «nada» original, es decir:

La operación $n$, de 3 a 5, agrega una tercera al representamen a expensas del «objeto semiótico». «___ es azul», por ejemplo, como la estructura rudimentaria de una proposición, reduce el estado del objeto del signo a nada más que la categoría vacía, $\varnothing$. Es entonces una entidad sumamente vaga, porque «es azul» cuanto menos dota al objeto no especificado con una cualidad potencial. Por otro lado, $q$ y $s$, de 4 a 6 y de 7 a 8 respectivamente, crean una pérdida de capacidad interpretativa (lo que será el enfoque más adelante). Y $p$, de 3 a 7 , requiere una transformación tanto del representamen como del interpretante. Por ejemplo, la evocación espontánea « ¿Váyase!», un signo 7 (legisigno dicente indi$c i a l$ ), se refiere al contexto de su emisión y se dirige $a$ alguien con algún propósito, aunque la carga de su interpretación se deje al destinatario del signo, ya que muy poca información ha sido especificada por el emisario. Sin embargo, esta evocación, dentro de algún contexto apropiado, se entiende, según las normas de comunicación, como si fuera una enunciación completa.

La operación $q$, que lleva 4 a 7 - o viceversa - abarca la transición de un tipo («type») que queda aún ambigua e indefinida a la esencia de la comunicación verbal a través de signos generales. El signo 7 «es cualquier tipo o ley general ... que requiere que cada una de sus ejemplificaciones estén afectadas por su objeto de tal manera que provea información acerca de este objeto» (CP:2.260). Este acto incluye el signo 4, para significar cierta información, y 6, por el operador $h$, para denotar el sujeto de esta información. Ejemplificaciones del signo 7 son típicas de las formas automatizadas y arraigadas (de-generadas) de significación. Tal 
es el caso cuando, como se mencionó arriba, los signos desaparecen del uso consciente, voluntario e intelectual, y entran en el uso inconsciente, involuntario y tácito. Ésta es la transición de lo que llama Peirce la generalidad a la vaguedad, o de lo que denomina Michael Polanyi (1958) la gravitación de la conciencia enfocada en algo hacia una conciencia subsidiaria - o, por decirlo así, de la simbolicidad a la iconicidad.

Estos signos pueden presentarse en una forma de-generada del signo 9 (una proposición), como, por ejemplo, oraciones «holofrásticas» («iHola!», «iPor Dios!», «iAy!»), o ciertos signos indiciales mas no lingüísticos que exigen una respuesta dentro de un contexto particular sin que haya un objeto específico de la proposición implícita (por ejemplo, un toque en la puerta, el sonido del teléfono). Tal uso arraigado y automatizado, y su respectiva interpretación - el resultado de un grado relativamente avanzado de lo que Peirce denomina hábito - se nota también en las evocaciones dentro de los «juegos de lenguaje» («lenguage games») de Wittgenstein $(1953,1958)$, el caso prototípico de los cuales es «Tabla!» («Slab!»). En la forma completamente vestida como el signo 9, esta expresión sería el equivalente de «Tráigame una tabla», «Ponga la tabla aquí», o algo por el estilo. Para que sean bien captadas, estas formas condensadas del uso de signos simbólicos deben ser acompañadas, dentro de contextos propiamente comunicativos (pragmáticos), por señales convencionales y no lingüísticas (gestos, ademanes, y otras expresiones no verbales).

Mientras el signo 7 implica cuanto menos lo esencial del predicado (icono) de una proposición, queda, sin embargo, como una forma medio vacía en vista de que no se la ha dotado del quién, del qué, del dónde y del cuándo del sujeto. L.S. Vygotsky (1962) cita ejemplos de esta clase de signo de textos literarios, sobre todo de la obra de Tolstoy. Describe cómo dos interlocutores, después de haberse conocido a fondo a través de los años, reducen algunas de sus expresiones a una forma muy reducida («holofrástica»), el significado de la enunciación quedando como reconocimiento tácito en la conciencia de los dialogantes. De esta manera al signo 7 se le llena, por una vía implícita y por un proceso inferencial mas no consciente, de sustancia significadora a través de los operadores $j$ (7 a 9), o $s$ (7 a 8).

La operación $i$ transforma el signo 6 (esto y no aquello) en un símbolo remático, 8, que sirve de manera explícita para especificar el sujeto o término de una proposición. Este signo se liga «con su objeto por una asociación de ideas generales de tal modo que su réplica evoca una imagen en la mente que, debido a ciertos hábitos o disposiciones de esta mente, tiende a producir un concepto general, y la réplica es interpretada como un signo de un objeto, el referente del concepto» (CP:2.261). Este signo es un símbolo de un tipo general, y por ende, un legisigno legítimo más bien que un sinsigno (índice) o cualisigno (icono). Su ejemplificación 
particular como réplica lo califica como un sinsigno remático indicial tanto como un legisigno remático indicial, ya que la imagen (icono) que sugiere puede aparecer (indicialmente) en la mente, dando luz a un concepto general (símbolo).

Además del hecho de que el símbolo remático es un mero este-aquíahora con respecto a la ejemplificación de un signo particular que se refiere a, por ejemplo, un camello (como un sinsigno remático indicial), puede ser una idea general, "camello», que, en términos semiológicos (saussureanos) relativamente limitados, es el significado («signifié»). Por lo tanto, «camello», como la mayoría de los símbolos, puede ser en un principio arbitrario, aunque a través del uso, y cargándose de hábito, llega a ser convencional y necesario. Y este símbolo, con su lejanía abstracta como generalidad de todos los camellos de carne y hueso del mundo «real» habiendo sido establecida, ahora puede, con la habituación sucesiva, alejarse cada vez más de las experiencias cotidianas. De la misma manera, todos los vocablos de las lenguas naturales son legisignos, y se relacionan directa o indirectamente con sus «objetos semióticos» respectivos. Además, entre las entidades léxicas de un lenguaje, cabe decir que la indexicalidad se destaca más en palabras (los «shifters» jakobsonianos) como «este», «aquí», y «yo» y la iconicidad es hipertrofiada por el uso de adjetivos como «radiante», «corto», «rápido» y «triste». El simbolismo, en cambio, se incorpora más adecuadamente en palabras-concepto y abstracciones que generalmente componen proposiciones y argumentos.

Para seguir adelante, la operación $j$ lleva el legisigno dicente indicial a un símbolo dicente, dicisigno, o proposición, que contiene un término o un compuesto de términos generados por $i, s$, u $o ; j$, igual que $k$, liga un nombre a su sustantivo o un sujeto a su predicado. Un sencillo «iHola!», un toque en la puerta, o el sonido del teléfono (signos 7), igualmente ofrecen una visión, aunque vaga, de sus respectivos objetos de la tercera categoría, y así señalan el camino hacia su plenitud como signos auténti$\cos$-proposiciones. Una proposición entera es un signo compuesto que consiste en un sujeto conectado a su «objeto semiótico» por su predicado a través de una asociación de ideas generales. Funciona como si fuera un término sencillo, salvo que su interpretante la significa según esté afectada por su «objeto semiótico». Esta significación requiere que una «conexión semiótica» exista entre la proposición y un suceso en lo «real semiótico». Por lo tanto el interpretante tiende desde el principio a interactuar con un término como si fuera un legisigno dicente indicial a través del operador $j$, ya que la ejemplificación particular del signo más bien que su uso general como término queda como enfoque inmediato del interpretante.

Pero el cuento aún no se ha acabado. Por su mera naturaleza, una proposición, funcionando como un término, es también un legisigno. Como 
el sinsigno dicente (que incluye un sinsigno remático indicial y el sinsigno icónico), es un signo compuesto a medida que envuelve un símbolo remático. Por eso es para su interpretante en cierto sentido también un legisigno icónico - la forma rudimentaria de un predicado- que transmite la información esencial, y un legisigno remático indicial - la base de un sujeto- - que indica el sujeto de la información.

Una proposición aislada, sin embargo, no puede gozar de un interpretante en el sentido auténtico. Un interpretante cabal en todo sentido es potencialmente - una potencialidad que no puede actualizarse en su totalidaddisponible por la generación de un argumento de un conjunto de proposiciones. Un argumento es el signo de ley. Lo que quiere decir Peirce por ley es «el pasaje de todas las ... premisas a ... conclusiones [que] tienden hacia la verdad. Su objeto, por lo tanto, debe manifestarse como generalidad; eso es, el argumento debe ser un símbolo. Como símbolo debe, además, ser un legisigno. Su réplica es un sinsigno dicente» (CP:2.263).

Por consiguiente el legisigno icónico, se carga de importancia axiomática, debido a su plenitud inicial como la incorporación del tercer nivel del representamen, mientras el objeto y el interpretante quedan en su nivel inicial, para tomar más vigor con la generación del argumento. Por esta razón $o$, transformando el signo 5 en el signo 8, es el primer operador capaz de transmutar un signo directamente a la columna simbólica en la figura 1. Por eso una veleta como signo llega a ser el «objeto semiótico» de un término general, «veleta», potencialmente capaz de referirse a toda clase de «veletas».

Es notorio que $c, h, k, l$ y $r$ magnifican el interpretante. Estos operadores representan los pasos preliminares hacia el desarrollo de hábitos, y el cambio - o la rotura de hábitos. El cambio de un hábito indica la «modificación de la tendencia que tiene una persona hacia la acción, lo que resulta de unas experiencias previas del empeño de su voluntad, o de sus actos, o de un conjunto de los dos tipos de causa» (CP:5.476). Por ende, tal como lo valorizado puede ser desvalorizado, tal como lo arraigado en la mente puede ser desarraigado, así el hábito incesantemente sufre grados sucesivos de modificación, sean voluntarios o no, y conscientemente ejercitados o no, de parte del agente semiótico.

\section{LA SIMBOLICIDAD: ¿EL ÁPICE DE LA SEMIOSIS? ... ¿O SU TIRANO?}

Surge la pregunta, entonces: ¿Cómo es que el $I$ sea capaz de unir (mediar entre) el $R$ y el $O$ ? Peirce se apropió del término «interpretante» en 
1867 en su ensayo, «Sobre una nueva lista de categorías», y nunca abandonó el concepto, aunque después amplió su significado sustancialmente. Según la definición de Peirce, el $I$ es de por sí un «transformador». Es como un intérprete dentro de un dominio vasto de signos, escribe Peirce, porque su función es análoga al acto de decir algo en una lengua que es semejante, si no igual, a lo que se ha dicho en otra lengua. Esta «inmanencia» del $I$ es fundamental. La noción de un «intérprete» generalmente ha implicado en la tradición occidental un sujeto «trascendente» dentro del dominio de los signos. En cambio, el «interpretante» de Peirce pone énfasis en el hecho de que el «intérprete» es inseparable de los signos que interpreta: es un signo más entre los signos - la enigmática y notoria ecuación, «hombre $\approx$ signo», de Peirce, que sólo hasta nuestros días se empieza a captar (Burks 1980; Fairbanks 1976; también Merrell 1991).

Dentro de un contexto propiamente lingüístico, David Savan (198788:41) observa que «traductor» («translatant») quizá fuera más adecuado que «interpretante», aunque éste sea más aplicable en general al universo entero de signos. El interpretante «traduce» signos en otros signos a la vez que traduce los signos en sus «objetos semióticos». Por ejemplo, si Ud. desconoce la palabra inglesa «city» y la busca en un diccionario español-inglés, encontrará «ciudad», una réplica del término general ciu$d a d$, a la derecha de «city». Ahora sabe que: (1) cualquier «objeto semiótico» denominado «ciudad» puede atribuirse de la misma forma a «city», (2) un conjunto de homo sapiens más un gran surtido de otros organismos domésticos y no domésticos, estructuras de diversos tipos, maquinaria burocrática, coches, camiones, autobuses, etc., es una city, y (3) ciudad es un signo de mediación entre city y la clase de «objetos semióticos» que caben dentro del término general «ciudad».

Savan (1987-88:41-44) afirma que estos tres pasos son los de un silogismo en el sentido de «Barbara» que producen un argumento, el signo 10, lo que es de importancia axial. Aunque Peirce en las últimas etapas de su pensamiento generalizó su definición del interpretante, en el fondo el término en su sentido más básico siguió como la fuerza motivadora que conduce a los signos hacia la plenitud de su significación. Es, por eso, apropiado que los operadores $c, h, k, l$ y $r$ sean pasos claves en el desarrollo del signo en el sentido de que abarcan «brincos», de niveles «inferiores» del interpretante a niveles «superiores». Por ejemplo, la imagen general (signo 2), que corresponde al término ciudad, se convierte en una idea general (signo 5) - aunque todavía vaga- que es la base de un predicado. Luego, la especificación de esto más bien que aquello (el signo 6), llega a ser un indicador (índice) más evolucionado del «objeto semiótico» que corresponde a aquello, o city (signo 7). City, a su vez, conduce al uso del término ciudad (signo 8), que, al unirse con el predicado « es city» para componer una proposición (signo 9), rela- 
ciona virtualmente al conjunto ciudad-city con una clase general de «objetos semióticos». Y subsecuentemente, un argumento (signo 10) puede generarse.

Los signos 8, 9, y 10 dentro de la columna del simbolismo en la figura 1 , revelan, en esta margen etérea de la semiosis, la centralidad del emisor/destinatario en diálogo tanto como del individuo en diálogo con su otro yo, su otro. El simbolismo, cuando menos en parte arbitrario, permite una autonomía parcial del signo con respecto a su «objeto semiótico» de modo que puede virar en direcciones tangenciales de los caminos convencionales y entrar en la comunicación autorreflexiva - la comunicación sobre el acto mismo de la comunicación. Entonces conduce al intérprete hacia una conciencia y un conocimiento: (1) del porqué de los signos, (2) de los procedimientos inferenciales y lógicos, y (3) de los mismos procesos de comunicación. Además, presenta un red de posibilidades de significación que es relativamente vasta, y hasta sin límites. Esta característica del símbolo revela, en los puntos extremos de la semiosis, un curso hacia las abstracciones sucesivas. Pero las abstracciones no tienen necesariamente que volverse fetiches, como en general ha sido el caso en el pensamiento moderno. Alfred North Whitehead (1925) nos advierte, en armonía con la «razonabilidad concreta» («concrete reasonableness») de Peirce, que el científico - y de hecho, todos nosotros- tiene forzosamente que entrar en el juego de abstracciones, pero siempre debe mantener un ojo sospechoso hacia el producto de sus esfuerzos mentales y experimentales.

La verdad persiste, sin embargo, de que las abstracciones sucesivas, para bien o para mal, marcan la historia de las sociedades occidentales en general. El dinero en billetes es más abstracto que el oro y el oro más abstracto que el trueque de materias en un mercado libre. Las computadoras son más abstractas que las máquinas de sumar, y éstas más abstractas que el ábaco. Desde los pictogramas, a los jeroglíficos, a los criptogramas y a la escritura fonocéntrica, o desde los palitos usados para computar, a la aritmética, al álgebra y a la teoría de los conjuntos, la abstracción sigue en aumento. A medida que los signos evolucionan, se les desprovee de su ropaje representativo. Se tornan signos desnudos que, aunque válidos en cuanto a su generalidad y su contenido cognoscitivo, quedan como signos de ausencia más bien que de presencia, sin eslabón a nada (el estándar del oro, los protocolos burocráticos, la manipulación formal de signos en la teoría de los conjuntos, el fonema arbitrario, la lógica booleana usada en las computadoras, los cuadros de Rothko, la narrativa autorreferencial de Beckett, la prosa autónoma respecto al mundo sentimental de RobbeGrillet, el silencio de John Cage, la página en blanco de Mallarmé). En otras palabras, un signo emerge con la capacidad de engendrar otros signos, que a la vez engendran otros, y en su totalidad se en- 
cierran dentro del palacio semiósico construido por su propia esencia, es decir, su ausencia, su nada. Se vuelven recursivamente autorreferenciales, generando interpretantes de una naturaleza implícita. Pero es la misma naturaleza la que les otorgó vida en su momento de nacer en el mundo semiótico.

Por lo tanto, la conexión entre «objetos reales» anteriores y los signos posteriores es ilusoria: el sueño antiguo -que sigue con vida en la actualidad - del poder del signo para representar el «objeto real» tal como es. Pero en realidad, los «objetos» conjurados para un destinatario no pueden ser más que partidarios de lo «real semiótico», porque los signos del discurso simbólico no se refieren directamente ni a «cosas» ni a su ausencia en el presente, sino a la ausencia de sus antepasados, que en un pasado remoto se convirtieron en meros «rastros» («traces»): retratos infieles, imágenes vagas, espejismos de ilusiones nostálgicas. Sin embargo, los símbolos prometen una posibilidad virtualmente sin límites de saber, de conocer $-\mathrm{y}$, desafortunadamente, de poder y control, las obsesiones de la modernidad. Y, por otro lado, son capaces de mentir, de engañar y de traicionar, una vez que los hábitos (a través del arraigo, la automatización) muestran su otra cara, su fuerza maligna.

El signo 7 representa la rotura principal abriendo la puerta a la susodicha semiosis autorreferencial, la comunicación sobre el acto comunicativo, y por lo tanto a un poder desaforado de la abstracción. Del otro lado de la moneda, 6 y 7 pueden ser el producto de la de-generación de 8 y 9 respectivamente, en una transmutación de la simbolicidad a la indexicalidad. El arraigo que inevitablemente resulta-es comparable al concepto de Spencer-Brown (1979:7) de diversos niveles sucesivos de espacios después de haber sido marcados y distinguidos. Como las sucesivas capas de una cebolla, pueden ser cruzados y re-cruzados para llegar, por fin, a los niveles más profundos, que, por el hecho de haberse sumergido cada vez más en la conciencia, se han integrado en la esfera del conocimiento y las actividades tácitas (automatizados, habitualizados) del individuo y de su comunidad.

Referente a la figura 1, si un signo tiene como destino el de quedar en el mismo nivel, traza sucesivas re-iteraciones en lazos cerrados, autorreferenciales y recursivos representados por las flechas circulares que se re-entran en sí mismas. Exclusivamente dentro de una de estas esferas cerradas, un signo, como si fuera un icono de sí mismo, indica no un «objeto semiótico» sino su propio contenido. Es, por decirlo así, tanto su propio interpretante como su propio interpretador. Pero, como ya se mencionó, nunca hay identidad absoluta después de cada re-iteración. Los lazos no pueden re-entrar en un estado igual al anterior. Al contrario, siempre hay una diferencia desde una re-entrada a otra, como un cristal ape- 
riódico, una molécula de DNA, o como la vida misma 7 . Sin embargo, por hábito, el agente semiótico, el intérprete de los signos a su alrededor, se empeña en imponer identidades a las diferencias. La identidad no queda simplemente allá, abierta a la vista de uno. Existe solamente en el ojo de su observador, como prisionero de/en sus caminos habituales.

Reaparece la pregunta, entonces: A pesar de mis advertencias con respecto al exceso de las formulaciones abstractas, ¿no es cierto que con los esquemas en las figuras 1 y 2 cometo yo mismo el pecado de la abstracción desaforada? A primera vista se puede suponer que así es. Demuestra Peirce que, por virtud de su ars cominatoria, el decálogo de signos — cada uno con su propia tricotomía - es capaz de engendrar una totalidad de $3^{10}$ o 59.049 signos, que luego redujo a 66 tipos fundamentales ( $C P: 8.343-47)$.

¡Eso sí parece una hazaña olímpica de la abstracción! Pero hay que tener en cuenta que para Peirce existe una continuidad entre azar o contingencia y ley, sentimiento y forma, cualidad y categoría, particularidades y generalidades, «objetos semióticos» y lo «real semiótico», signos mentales y signos del mundo material. Peirce nunca quiso divorciar la existencia concreta de las abstracciones puras.

Hay que recordar también que, respecto a sus 59.049 signos, Peirce escribía sobre un proyecto para el futuro lejano titulado «La lógica, considerada como semiótica», que incluiría una inquisición sobre las tres «modalidades de ser» (es decir, sobre la significación) ${ }^{8}$. La primera modalidad era la de lo posible, que es en todos sus puntos «incapaz de una actualización perfecta por el hecho de que es esencialmente vaga, si no por otra razón. Porque lo que no está sujeto al principio lógico de la contradicción es esencialmente vago» (Hardwick, 1977:81). La segunda es la de los existentes, los «objetos» como producto de «acontecimientos» en el mundo exterior. Y la tercera consiste de lo necesario, a través de hábito, o algo expresable en una proposición general. Incluye «lo que podamos saber por razones lógicamente válidas» (Hardwick, 1977:82). En seguida Peirce denota estas modalidades tono, rasgo nominal («token»), y tipo («type»), que corresponden a los cualisignos, sinsignos y legisignos. La clave, con respecto a la primera modalidad, es la vaguedad, que en conjunto con la generalidad, es responsable por la actualización -aunque siempre imperfecta (incompleta) — de la red de signos para una comunidad de agentes semióticos ${ }^{9}$. Esta vaguedad, por vía de la su-

7 Véase a Schrödinger (1967) quien postuló, varios años antes del descubrimiento de DNA, que la vida comienza con el equivalente de un cristal aperiódico (también Hoffmeyer and Emeche [1991], Lofgren [1978, 1981a, 1981b, 1984], y Pattee [1969, 1972, 1977, 1986]).

8 Peirce usaba las palabras "modos de ser" ("modes of being"), que reemplazaré por "modos de significación" para evitar términos de la filosofia "esencialista" contemporánea.

9 Cabe decir que Rescher and Brandom (1979) demuestran cómo la generalidad y la vaguedad son equivalentes a los principios de lo incompleto ("incompleteness") y la inconsistencia ("inconsistency"), en la prueba de Kurt Gödel de la limitación de todos los sistemas formales. 
cesiva diferenciación que se manifiesta con cada actualización de un signo, y por próxima que sea a la perfección o la idealización, revela la naturaleza concreta de los signos dentro de sus contextos respectivos. Y, por eso, la tarea de la interpretación de estos signos contextualizados descansa en el intérprete, suspendido dentro de su propio contexto.

Una breve divagación, creo, es ahora necesaria para especificar el concepto de Peirce acerca de la interacción dialógica entre los emisores y destinatarios de signos. Peirce escribe que un signo que queda indeterminado en algún sentido es vago a medida que «reserva la determinación futura de su significación para algún otro signo concebible» (CP:5.447). Por ejemplo, la enunciación coquetona, «Yo podría echarte unos piropos bien simpáticos esta noche», sugiere, mas no especifica ni autoriza, una interpretación particular. Alguna determinación futura de la frase como signo compuesto depende de otros signos potencialmente generados en otro momento, y en general según la discreción del emisor de la enunciación inicial. En este sentido, cada enunciación, en grado menor o mayor, «deja el derecho de su exposición sucesiva al enunciador; y por eso, a medida que un signo es indeterminado, es vago, a menos que se carge expresamente o por una convención social abiertamente reconocida de una interpretación general» $(C P: 5.447)$.

Parece que el principio de la vaguedad de Peirce sigue una «lógica» poco ortodoxa, por no decir completamente extraña. El significado de la enunciación, tal como se presenta en el momento o según se interpreta en algún momento en el porvenir por otros signos o por el emisor, puede estar sujeto a cambios, casi sin límite, de puntos espacio-temporales a otros -así como el mundo forzosamente gira, también sufren transmutaciones todos los signos tanto como sus significados. De esta manera, no se puede decir que la ley aristotélica de la no-contradicción tiene forzosamente que estar en vigor. Sin embargo, es obvio que el principio de la vaguedad marcha al compás del concepto general del signo según Peirce. Cuando consideramos que un signo incluye «cada tipo de pensamiento y no solamente los signos exteriores», tenemos que darnos cuenta de que un signo no solamente debe ser indeterminado (vago) en el sentido subjetivo, sino también indeterminado en el sentido objetivo (el «objeto semiótico» no es directamente determinado por el signo mismo) y por lo tanto es «objetivamente general» en tanto que «extiende al destinatario el privilegio de llevar a cabo su determinación futura» $(C P: 5.447)$.

Entonces hay un principio de generalidad que complementa el principio de vaguedad. Por ejemplo, la proposición general, «El hombre es mortal», un dicisigno, es del orden de una categoría tercera genuina, en contraste con la posibilidad presentada por la enunciación coquetona mencionada arriba, que pertenece a la categoría primera. En contraste con el signo vago, una respuesta al signo general, «El hom- 
bre es mortal», que evoca la pregunta «¿Cuál hombre?», depende sobre todo del destinatario o intérprete. El puede decidir por sí mismo cuál hombre, cuántos hombres, o si se trata de hombres y mujeres o de toda la humanidad, tal como quiera. Pero, si desea verificar la proposición en sentido absoluto, no puede hacerlo hasta que haya sido testigo efectivo de la vida y muerte de cada ser humano, pasado, presente y futuro. Entonces el principio del medio excluido de la lógica clásica no se aplica necesariamente al principio peirceano de la generalidad. Con razón Peirce define el «interpretante final» o «último» como el efecto pleno de un signo sólo si su propósito o intención ha sido logrado totalmente. Este «ha sido» quedará en el futuro indefinido, al final alcanzable, en un sentido teórico-abstracto, pero no en el sentido práctico y concreto. En este espíritu, Peirce escribe más adelante que «quizás un par de definiciones más científicas serían las siguientes: cualquier signo es general en tanto que el principio del medio excluido no se aplica, y es vago en tanto que el principio de contradicción no se aplica» (CP:5.448).

En la medida en que una declaración quede indeterminada, que es el caso de todas las declaraciones generadas en una comunidad de parlantes, no hay ninguna garantía absoluta que sea idéntica a sí misma. Entonces no es necesariamente el caso que sea en un momento dado ni verdadera ni falsa, y existe la posibilidad que pueda ser verdadera y falsa. En un extremo tenemos la vaguedad y la indeterminación de la categoría primera y en el otro extremo la generalidad y la indeterminación de la tercera. Entre las dos está el mundo de los acontecimientos semióticos actualizados (la categoría segunda de los signos), y cualquiera de ellos puede, en un momento dado, estar sometido a una interpretación por algún sujeto semiótico. Se le puede atribuir, de esta manera, una interpretación relativamente definida, pero en el próximo momento puede ser arrebatado por el diluvio semiósico para cargarse de otros significados completamente distintos (CP:5.449).

De esta manera, en cada momento de nuestra vida como agentes semióticos existe, para nosotros, una serie virtual $-\mathrm{y}$ sin fin - de posibilidades (de categoría primera), una porción infinitesimal de las cuales puede actualizarse (según la categoría segunda), sean signo-acontecimientos en el mundo exterior, o signo-ideas en la mente. De otro lado, lo ideal o general (de la categoría tercera) es de tal naturaleza que, con suficiente tiempo, y dada una comunidad humana sin límites, cada una de las posibilidades puede ser actualizada y juzgada como verdadera o falsa. Pero este signo cabal (general) está destinado a quedar incompleto en nuestro mundo de individuos y de comunidades finitos y falibles; por ende la verdad o la falsedad en sentido absoluto no se alcanzará. Y el signo posible (vago) es tal como si no existiera la certidumbre absoluta de que sí es verdadero o falso, porque «dos proposiciones contradictorias pueden ser 
igualmente verdaderas, aunque su combinación en un conjunto no sea posible» $(C P: 3.527)$. Es decir, cada una de las posibilidades de por sí es vaga, no distinta.

Este concepto peirceano, en su forma esquemática, constituye la esencia de lo que el lógico-semiótico norteamericano previó para su «lógica en el sentido más amplio posible». Según las premisas de la lógica clásica, cada propiedad, una vez que su identidad está discernida, es o verdadera o falsa. Pero para la lógica más general de Peirce, mientras esta propiedad permanezca indeterminada - lo que será inevitablemente el caso, organismos limitados que somos - no es necesariamente la verdad que es o verdadera o falsa, y no es necesariamente falso que no sea verdadera $\mathrm{y}$ falsa.

Dada esta incertidumbre en el corazón de la semiótica, la modalidad de significación depende del ángulo desde el cual nosotros percibimos el signo y el «objeto semiótico». Y como intérpretes, la responsabilidad de completar la determinación del significado del signo hasta donde sea posible nos cae a nosotros. De modo que la semiótica no puede ser una panacea técnica, metodológica, o teórica capaz de convertir fenómenos en formas y acontecimientos en fórmulas. En vez de las dicotomías tradicionales de instinto/razón, sentimiento/lógica, pasión/objetividad e imaginación/percepción empírica, Peirce concibió al mundo como una fusión de naturaleza y cultura, y de lo que es propiamente mental y lo que es «real». Todo consiste en signos. Y la esfera de la semiosis es de fluidez en vez de una serie de instantes sincrónicos en el sentido de Saussure. Es como un video en perpetuo movimiento en vez de una serie de retratos estáticos.

\section{Referencias bibliográficas}

BAER, E. (1988): Medical Semiotics. Lanham: University Press of America.

BuczunSKA-GarewICZ, H. (1979): «The Degenerate Sign.» Semiosis 13, 4-16.

- (1983): «The Degenerate Sign». En Semiotic Unfolding (Proceedings of the Second Congress of the International Association for Semiotic Studies, Vienna, July 1979), Tasso Borbé (ed.) (= Approaches to Semiotic 68), vol., 43-50. Berlín : Mouton de Gruyter.

BurKS, A. W. (1980): «Man: Sign or Algorithm? A Rhetorical Analysis of Peirce's Semiotics.» Transactions of the Charles S. Peirce Society 16 (4), 279-92.

FAIRBANKS, M. J. (1976): «Peirce on Man as a Language: A Textual Interpretation».

Transactions of the Charles S. Peirce Society 32, 75-104. 
GoRlÉE, D. (1980): «Degeneracy: A Reading of Peirce's Writing». Semiotica 81 (1/2), 71-92.

HARDWICK, Ch. S. (ed.) (1977): Semiotics and Significs: The Correspondence between Charles S. Peirce and Victoria Lady Welby. Bloomington: Indiana University Press.

HoFFMEYer J., and EmMEChe, C. (1991): «Code Duality and the Semiotics of Nature», 117-65. En On Semiotic Modeling, M. Anderson and F. Merrel (eds.). Berlin: Mouton de Gruyter.

LofGREN, L. (1978). «Some Foundational Views on General Systems and the Hempel Paradox». International Journal of General Systems 4, 243-53.

- (1981a): «Knowledge of Evolution and Evolution of Knowledge». En The Evolutionary Vision, E. Jantsch (ed.), 129-51. Boulder, Co: Westview.

- (1981b): «Life as Autolinguistic Phenomenon». En Autopoiesis: A Theory of Living Organization, M. Zeleny (ed.), 236-49. New York: North-Holland.

- (1984): «Autology of Time». International Journal of General Systems n. ${ }^{\circ} 10,5-14$.

Marty, R. (1982): «C.S. Peirce's Phaneroscopy and Semiotics». Semiotica 41 (1/4), 169-81.

Merrell, F. (1985): Deconstruction Reframed. West Lafayette, IN: Purdue University Press.

- (1991): Signs Becoming Signs: Our Perfusive, Pervasive Universe. Bloomington: Indiana University Press.

Pattee, H. H. (1969): «How Does a Molecule Become a Message?». Developmental Biology, Supplement 3, 227-33.

- (1972): «Laws and Constraints, Symbols and Languages». En Towards a Theoretical Biology, 4, C. H. Waddington (ed.), 248-58. Edinburgh: University of Edinburgh Press.

- (1977): «Dynamic and Linguistic Modes of Complex systems». International Journal of General Systems 3, 259-66.

- (1986): «Universal Principles of Measurement and Language Functions in Evolving Systems». En Complexity, Language and Life: Mathematical Approaches, J. L. Casti and A. Karlqvist (eds). 268-81. New York: Springer-Verlag.

PEIRCE, Ch. S. (1931-35): Collected Papers of Charles Sanders Peirce, vols. 1-6, C. Hartshorne and P. Weiss (eds.). Cambridge: Harvard University Press (referencias a Peirce serán designadas $\mathrm{CP}$ )

- (1958): Collected Papers of Charles Sanders Peirce, A. W. Burks (ed.), vols. 7-8. Cambridge: Harvard University Press (referencias a Peirce serán designadas $\mathrm{CP}$ ).

Polanyi, M. (1958): Personal Knowledge. Chicago: The University of Chicago Press.

Rescher, N. and Brandom, R. (1979): The Logic of Inconsistency: A Study of NonStandard Possible World Semantics and Ontology. Oxford: Blackwell.

Rotman, B. (1987): Signifying Nothing: The Semiotics of Zero. New York: St. Martin's.

Savan, D. (1987-88): An Introduction to C. S. Peirce's Full Systems of Semeiotic. Toronto: Monograph Series of the Toronto Semiotic Circle, 1.

SChröDInGER, I. (1967): What is Life? and Matter and Mind. Cambridge: Cambridge University Press.

SPENCER-BRown, G. (1979): Laws of form. New York: E. P. Dutton.

Tursman, R. (1987): Peirce's Theory of Scientific Discovery: A System of Logic Conceived as Semiotic. Bloomington: Indiana University Press. 
VyGOTSKY, L. S. (1962): Thought and Language, trans. E. Hanfmann and G. Vakar. Cambridge: MIT Press.

WhITEHEAD, A. N. (1925): Science and the Modern World. New York: MacMillan.

Wittgenstein, L. (1953): Philosophical Investigations, trans. G. E. M. Anscombe. New York: MacMillan.

- (1958): The Blue and the Brown Books. New York: Harper and Row. 